\title{
EFFECT OF TWEEN 80 AND MOISTURE REGIMES ON ENDOSULFAN DEGRADATION BY PSEUDOMONAS AERUGINOSA
}

\author{
R. JAYASHREE* - N.VASUDEVAN \\ Centre for Environmental Studies, Anna University, Chennai-600 025, Tamil nadu, India \\ (phone: + 091- 9884787202) \\ *Corresponding author \\ e-mail : p_tamil@yahoo.com \\ (Received $1^{\text {st }}$ October 2006 ; accepted $6^{\text {th }}$ July 2009)
}

\begin{abstract}
The problem of endosulfan bioremediation is poor solubility and restriction of appropriate biocatalyst. One promising approach in increasing the bioavailability of this organic compound is addition of surfactants. The synthetic surfactant Tween 80 was non-toxic to soil microorganisms and inert to the soil matrix and had the additional benefit of causing an enhanced dissolution rate for single compounds. The degradation of alpha and beta endosulfan by Pseudomonas aeruginosa with Tween 80 and different moisture regimes (flooded and non-flooded conditions) was studied. The rate of degradation was maximum (92\%) in non-flooded and Tween 80 added soil; the bacterial count was also maximum. The addition of synthetic surfactant Tween 80 enhanced the solubility and degradation of endosulfan. The degradation of both the isomers were observed and accompanied with formation of endodiol and endosulfan sulfate.
\end{abstract}

Keywords: Tween 80; Moisture regimes; Endosulfan; Degradation; Pseudomonas aeruginosa

\section{Introduction}

Endosulfan is a chlorinated cyclodiene insecticide currently used throughout the world for the control of numerous insects in a wide variety of food and non-food crops. Endosulfan has been ubiquitously detected in the atmosphere, soils, sediments, surface waters, rainwater's and foodstuffs [1]. Endosulfan comprises two-parent isomers alpha and beta endosulfan and the alpha to beta ratio of technical endosulfan is about 7:3 and both isomers are extremely toxic to aqueous organisms. Many bacteria and fungi including Cornybacterium sp., Nocardia sp., Mycobacterium sp., Pseudomonas fluorescens, Penicillium sp., Aspergillus sp., Phanerochaete chrysosporium have been reported to be endosulfan degraders [2]. Endosulfan could be degraded by attack on the sulfite group by oxidation and or hydrolysis to form the toxic endosulfan sulfate and the non-toxic endosulfan diol respectively [3]. The problem of endosulfan bioremediation is poor solubility and restriction of appropriate biocatalyst. One promising approach in increasing the bioavailability of this organic compound is addition of surfactants.

The synthetic surfactant Tween 80 was non-toxic to soil microorganisms and inert to the soil matrix and had the additional benefit of causing an enhanced dissolution rate for single compounds [4]. Despite the many advantages of surfactin over chemical surfactants for bioremediation, its use has been limited on account of the high production cost. The uptake of micellar n-decane and n-tetradecane was stimulated by a biodegradable synthetic surfactant resulting in higher growth rates. This was probably caused by direct uptake of the hydrocarbons along with the micelles [5]. The 
synthetic surfactant at low concentrations may be useful for bioremediation of sites contaminated with hydrophobic pollutants [6]. The addition of Tween 80 stimulated utilization of hexadecane by several strains of Pseudomonas aeruginosa [7]. Pseudomonas aeruginosa when combined with Tween 80 effectively enhanced the solubility and degradation of phenanthrene and they also reported that Tween 80 is biodegradable [8]. The oxygen uptake rate of bacterial cells was not affected in the presence of surfactants. They also reported that surfactant concentrations up to $10 \mathrm{~g} / \mathrm{L}$ could be used without any toxicity effect on microorganisms [9].

The environmental fate of endosulfan in soils is influenced by the $\mathrm{pH}$, texture, moisture content and also by the presence of organic matter and co-pollutants. The rate of degradation is a function of the prevailing temperature, moisture regime, the content, type of organic matter and clays present [10]. The biodegradation of hydrophobic substances was affected by soil moisture, $\mathrm{pH}$, mineral nutrients, micronutrients, organic supplements, treatment rate, treatment frequency and incubation temperature [11].

In the present study we have isolated an endosulfan degrader, Pseudomonas aeruginosa through intensive screening from endosulfan polluted soil samples. In addition, Tween 80 was added to the bacterial culture at different moisture regimes (Flooded and non-flooded) conditions to enhance the bioavailability and complete elimination of endosulfan from the contaminated soil.

\section{Materials and Methods}

\section{Chemicals}

Endosulfan standards ( $\alpha$-endosulfan, $\beta$-endosulfan and its metabolites) were purchased from M/s. Chem Service Inc., West Chester, USA with a purity of $98 \%$. A standard was prepared by dilution of the stock solution $(1000 \mu \mathrm{g} / \mathrm{mL})$ of each compound and stored in a refrigerator at $4^{\circ} \mathrm{C}$. All stock solutions were prepared and stored at $-20^{\circ} \mathrm{C}$. Commercial endosulfan was purchased from Jayaprakash Fertilizers Agency, Thiruvallur district. The non-ionic surfactant Tween 80 and 2-phenoxy ethanol were obtained from Sigma Chemical Co., USA. All other chemicals, solvents and reagents used in the study were of analytical grade.

\section{Enrichment and isolation of bacterial strain}

Two grams of soil samples was taken in a 250-mL Erlenmeyer flask containing 50 $\mathrm{mL}$ of liquid mineral medium (Ammonium chloride- $1.0 \mathrm{~g}$, Potassium dihydrogen orthophosphate-2.0g, Dipotassium hydrogen orthophosphate - 7.5g, Magnesium sulphate - 0.2g, Sodium chloride - 0.5g, Calcium carbonate - 0.2g, Glucose $-1.0 \mathrm{~g}$, Distilled water - $1.0 \mathrm{~L}, \mathrm{pH}-7.8$ and agar $15 \%$ was added to solid medium) with $50 \mu \mathrm{g} / \mathrm{mL}$ of endosulfan and was incubated for 7 days in a rotary shaker (IKA, Germany) at $130 \mathrm{rpm}$. Five millilitres of culture broth from individual flask culture was re-inoculated to $50 \mathrm{~mL}$ of endosulfan mineral salt medium and further cultured at $30^{\circ} \mathrm{C}$ for 7 days. Enrichment of the culture was done by repeated transfers. Then 0.1 $\mathrm{mL}$ of culture broth was plated on solid endosulfan mineral salt medium for isolating single colonies. The single colonies were characterized and identified as a 
Pseudomonas aeruginosa using biochemical tests (Table 1.). The culture was maintained on mineral agar slants.

Table 1. Biochemical test for Pseudomonas aeruginosa

\begin{tabular}{|l|l|}
\hline TEST & RESULTS \\
\hline INDOLE & NEGATIVE \\
\hline CITRATE UTILIZATION & UTILISED \\
\hline T. S. IRON AGAR & K / K \\
\hline $\begin{array}{l}\text { FERMENTATIVE / OXIDATIVE (HUGH } \\
\text { LEIFSON) }\end{array}$ & OXIDATIVE FERMENTATION \\
\hline OXIDASE & POSITIVE \\
\hline
\end{tabular}

\section{Growth studies}

A loopful of P.aeruginosa grown on mineral agar slant was inoculated into a 250 $\mathrm{mL}$ conical flasks containinig $50 \mathrm{~mL}$ medium amended with endosulfan as substrate. The flasks were kept for $24 \mathrm{~h}$ on an orbital rotary shaker set at $130 \mathrm{rpm}$ at $30^{\circ} \mathrm{C}$ for the growth of the organism. Growth was measured at $24 \mathrm{~h}$ as viable cell count as well as turbidity at $550 \mathrm{~nm}$. The cells were harvested by centrifugation at $5000 \mathrm{~g}$ for $10 \mathrm{~min}$. The cell pellet was washed twice in $15 \mathrm{mM}$ phosphate buffer, $\mathrm{pH}$ 7. The washed cells were used for degradation study $\left(2 \times 10^{5} \mathrm{CFU}\right)$.

\section{Soil}

The soil selected for this study was collected from Thiruvallur district had no previous exposure to pesticides and was classified as sandy loam. The soil was air dried and sieved through $2 \mathrm{~mm}$ sieve. The carbon content of the soil was estimated using TOC analyzer (Analytic gena, micro $\mathrm{C}$ ). The $\mathrm{pH}$ of the sample was estimated as per the methods of [12]. $\mathrm{pH}$ of the soil was 7.3 , organic carbon $0.12 \%$. Commercial endosulfan 35EC was added to the soil to give a concentration of $2.35 \mathrm{mg} / \mathrm{g}$ active ingredient (compound that kills or controls the target pest). After air drying for $24-48$ $\mathrm{h}$, the soil was pulverized and used for degradation studies.

\section{Degradation of endosulfan in flooded and nonflooded condition}

For each moisture regimes, 4 sets were made containing $20 \mathrm{~g}$ soil in each set's and Tween 80 was added at CMC (A phenomenon unique to surfactants is the selfassembly of molecules into dynamic clusters called micelles. Micelle formation occurs above a critical concentration of surfactant monomers referred to as the Critical Micelle Concentration [13]. Three replicates were maintained for each set. Experimental details were presented in Table 2. All the experimental sets were received $6 \mathrm{~mL}$ of mineral medium without glucose. To maintain the flooded condition, $20 \mathrm{~mL}$ of mineral medium was added as an addition. All sets were kept at $30^{\circ} \mathrm{C}$ for 8 weeks and $1.2 \mathrm{~g}$ samples were taken at weekly intervals to quantify the residual endosulfan present in each soil sample. 
Table 2. Experimetal set up

\begin{tabular}{|c|l|}
\hline T1 & Soil (flooded) + Endosulfan \\
\hline T2 & Soil (flooded) + Endosulfan + Pseudomonas aeruginosa \\
\hline T3 & Soil (non-flooded) + Endosulfan \\
\hline T4 & Soil (non-flooded) + Endosulfan + Pseudomonas aeruginosa \\
\hline T5 & Soil (flooded) + Endosulfan + Tween $80(0.1 \mathrm{~g} / \mathrm{L})$ \\
\hline T6 & Soil (flooded) + Endosulfan + Tween $80(0.1 \mathrm{~g} / \mathrm{L})+$ Pseudomonas aeruginosa \\
\hline T7 & Soil (non-flooded + Endosulfan + Tween $80(0.1 \mathrm{~g} / \mathrm{L})$ \\
\hline T8 & Soil (non-flooded) + Endosulfan + Tween $80(0.1 \mathrm{~g} / \mathrm{L})+$ Pseudomonas aeruginosa \\
\hline
\end{tabular}

\section{Bacterial count}

During the degradation process, the bacterial population (plate count technique) was monitored at weekly intervals. One gram of soil was taken and incubated for $30 \mathrm{~min}$ with $100 \mathrm{~mL}$ of sterile water at $30^{\circ} \mathrm{C}$ at $150 \mathrm{rpm}$. A $100 \mu \mathrm{L}$ sample of appropriate dilution of the soil suspension was inoculated onto nutrient agar plates. The plates were incubated at $30^{\circ} \mathrm{C}$ for $24 \mathrm{~h}$ and the number of colonies were counted.

\section{Extraction of endosulfan residues}

In the experiment with flooded and non-flooded soils, the volumes in all the bottles were raised to $25 \mathrm{~mL}$ with mineral medium before harvesting. An equal volume of ethyl acetate was added and samples were shaken on an orbital shaker at $220 \mathrm{rpm}$ for 30 minutes. Contents were then transferred to a separating funnel and the organic layer was collected. The aqueous layer was extracted three more times with $25 \mathrm{~mL}$ of ethyl acetate. Ethyl acetate fractions were pooled, passed through anhydrous sodium sulfate $(5 \mathrm{~g})$ and florosil $(2 \mathrm{~g})$ mixture [14] and evaporated at room temperature.

\section{Chromatographic analysis}

Pesticide residue was dissolved in acetone and an aliquot containing 5-10 $\mu \mathrm{g}$ of endosulfan was spotted on a silica gel plate and the chromatogram was developed in hexane: chloroform: acetone $(9: 3: 1)$. The separated spots were visualized by spraying the chromogenic reagent $\left(\mathrm{AgNO}_{3}\right.$ in 2-phenoxy ethanol) [15]. For gas chromatography, the residual pesticide was dissolved in $1 \mathrm{~mL}$ of acetone, diluted to $10^{6}$ times with n-hexane, and analysed as per the above said procedure.

One microlitre from each of the final residue solutions was injected into the GC (Chemito) model 1000 chromatography equipped with a packed glass column (4'x1/8", filled with 60-80 mesh coated over chromosorb with a mixture of $1.5 \% \mathrm{OV}$ 17 and $1.95 \%$ QF) with ECD (Electron Capture Detector) for residue analysis in an injector temperature of $220^{\circ} \mathrm{C}$, oven temperature $190^{\circ} \mathrm{C}$, detector temperature $280^{\circ} \mathrm{C}$ and nitrogen as carrier gas $(27 \mathrm{~mL} / \mathrm{min})$. The qualitative identification of the endosulfan present in the samples was performed by comparing the relative retention times (RRT) with respect to the standard, for each peak in the real sample chromotogram to those (RRT) in the standard mixture chromotogram. The quantitative determination was performed by using the relative peak areas (RPA) and the relative concentrations (RC). 


\section{Results and Discussion}

\section{Effect of flooded and non-flooded condition on endosulfan degradation}

Treatment unit T2 at flooded condition showed $40 \%$ of alpha and $29 \%$ beta degradation, the bacterial population was $53 \times 10^{6} \mathrm{CFU} / \mathrm{g}$ of soil. The control unit T1 recorded $10 \%$ of alpha and $8 \%$ of beta degradation; the bacterial population was $63 \mathrm{x}$ $10^{4} \mathrm{CFU} / \mathrm{g}$ of soil (Fig. 1.).

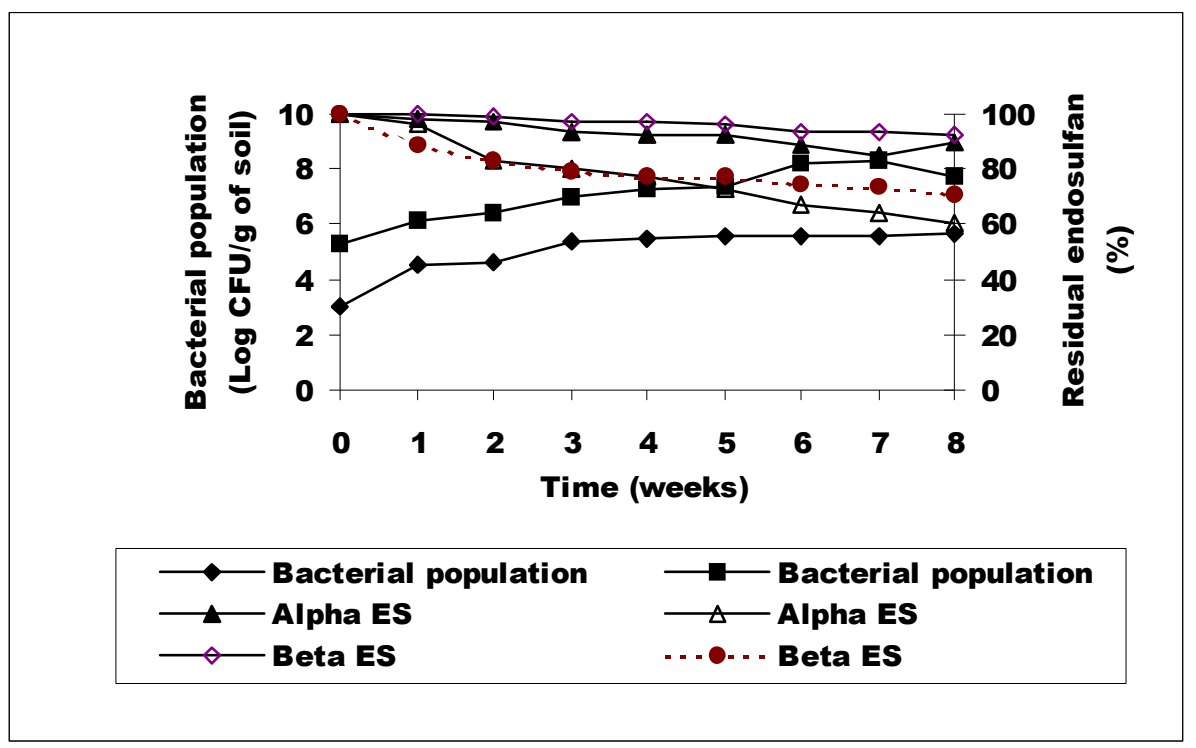

Figure 1. Degradation of endosulfan (ES) at flooded condition

The unit T4 inoculated at non-flooded condition showed $82 \%$ alpha and $60 \%$ beta endosulfan degradation, the bacterial population was $62 \times 10^{8} \mathrm{CFU} / \mathrm{g}$ of soil. The control unit T3 showed $14 \%$ of alpha endosulfan and $10 \%$ of beta endosulfan degradation where the bacterial population was $28 \times 10^{4} \mathrm{CFU} / \mathrm{g}$ of soil (Fig.2).
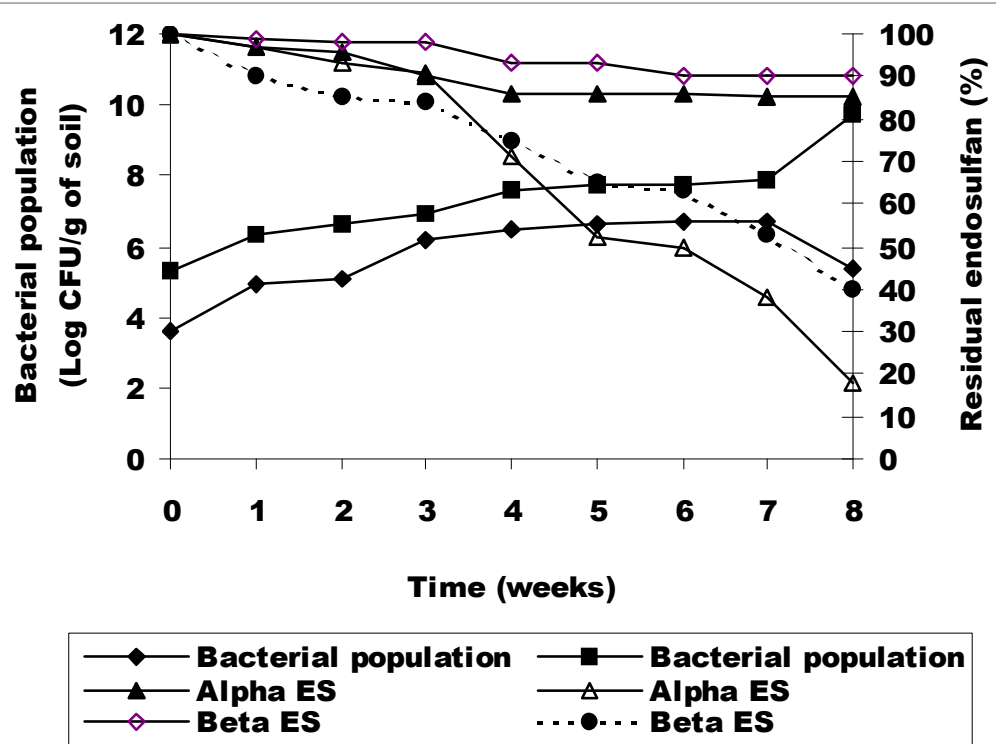

Figure 2. Degradation of endosulfan (ES) at non- flooded condition 
During the degradation process, the metabolites such as endosulfan diol and endosulfan sulfate were formed at flooded and non-flooded conditions (Fig. 3).

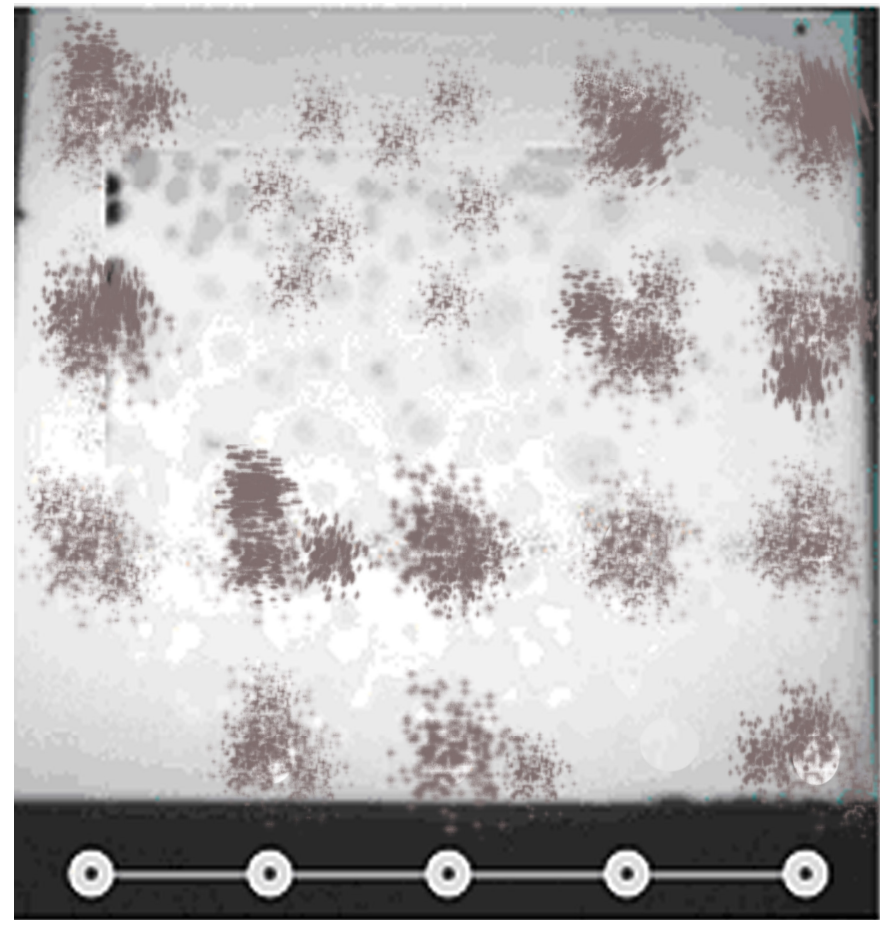

$\begin{array}{lllll}\text { (a) } & \text { (b) } & \text { (a) } & \text { (b) } & \\ \mathrm{F} & \mathrm{F} & \mathrm{NF} & \mathrm{NF} & \text { Std }\end{array}$

Figure 3. Thin layer chromatogram showing the metabolites formed during the degradation of $\alpha$ and $\beta$ endosulfan at flooded $(F)$ and non-flooded

(NF) condition

(1) $\alpha$ - endosulfan, (2) $\beta$-endosulfan, (3) Endosulfan sulfate

(4) Endodiol

(a) without Pseudomonas aeruginosa

(b) with Pseudomonas aeruginosa

The maximum degradation at non-flooded condition is mainly due to increased growth and activity of the bacteria in non-flooded condition [16]. This could be due to better bioavailability of endosulfan and optimal biotic activity of cells at this condition.

\section{Effect of Tween 80 on endosulfan degradation}

Microbial methods to remediate hydrophobic organochlorines contaminated soils are often limited by low substrate solubilities which can reduce bioavailability to the degrading microorganisms [17]. Use of Tween 80 as a means of increased bioavailability of hydrophobic endosulfan to microorganisms under different moisture regimes (flooded and non-flooded conditions) were studied.

The unit T6 (flooded with Tween 80 ) recorded $48 \%$ of alpha and $38 \%$ of beta endosulfan degradation. The bacterial population in the soil was $36 \times 10^{8} \mathrm{CFU} / \mathrm{g}$ of soil. The control unit (T5) showed $10 \%$ of alpha endosulfan and $6 \%$ of beta 
endosulfan degradation, the bacterial population in the soil was $5 \times 10^{5} \mathrm{CFU} / \mathrm{g}$ of soil (Fig. 4.).

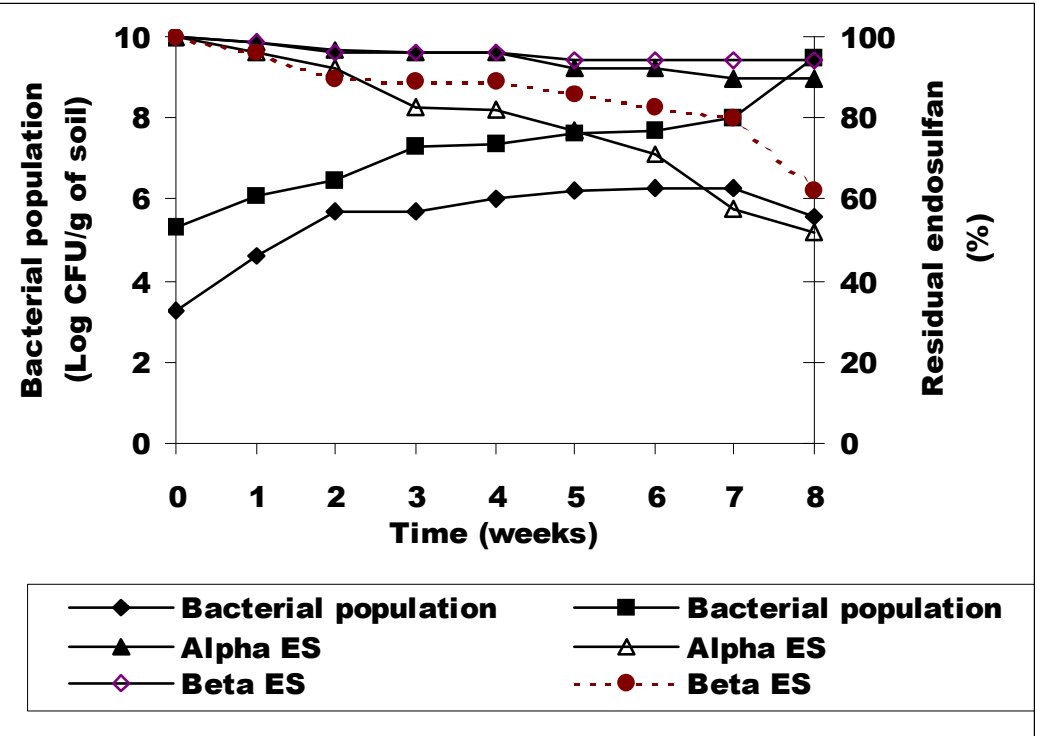

Figure 4. Degradation of endosulfan (ES) with Tween 80 at flooded condition

When compared to Tween 80 with flooded and non-flooded conditions, Tween 80 with non-flooded conditions recorded maximum degradation of endosulfan isomers ( $92 \%$ of alpha and $87 \%$ of beta), the bacterial population in the treatment unit T8 was $95 \times 10^{9} \mathrm{CFU} / \mathrm{g}$ of soil. The control unit (T7) showed $13 \%$ of alpha and $10 \%$ of beta endosulfan degradation. The cell growth was increased to $3 \times 10^{6} \mathrm{CFU} / \mathrm{g}$ of soil (Fig.5.)

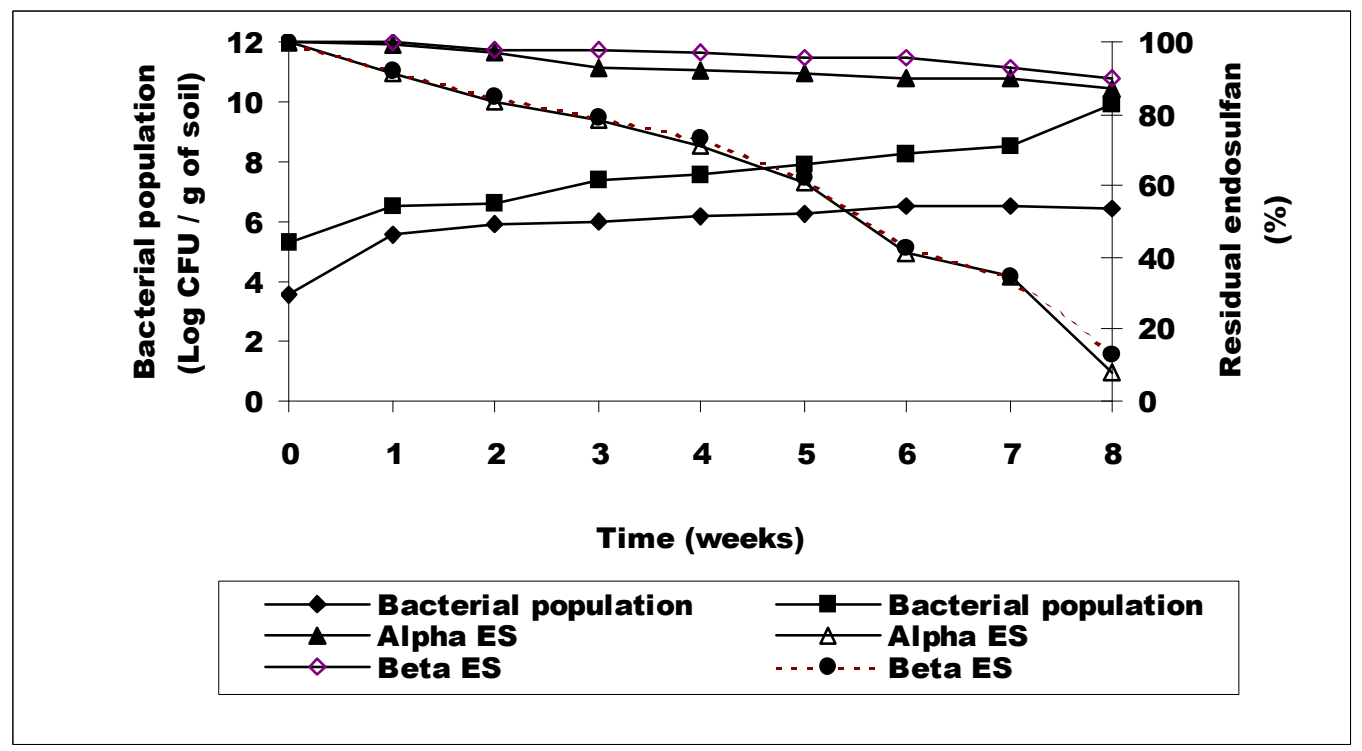

Figure 5. Degradation of endosulfan (ES) with Tween 80 at non-flooded condition

Thin layer chromatography results of endosulfan diol and endosulfan sulfate formed during the degradation process are given in the Fig. 6. 


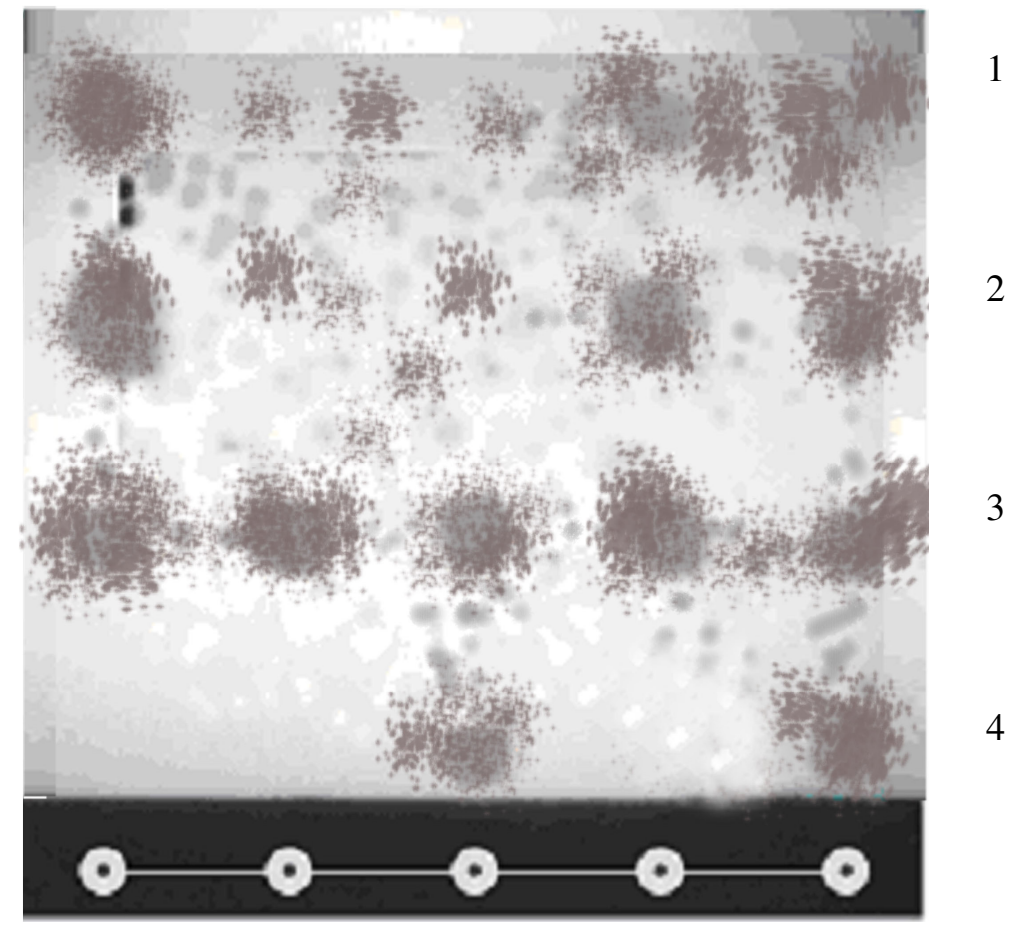

$\begin{array}{lllll}\text { (a) } & \text { (b) } & \text { (a) } & \text { (b) } & \\ \mathrm{F} & \mathrm{F} & \mathrm{NF} & \mathrm{NF} & \text { Std }\end{array}$

Figure 6. Thin layer chromatogram showing the metabolites formed during the degradation of $\alpha$ and $\beta$ endosulfan at flooded $(F)$ and non-flooded $(N F)$ condition with Tween 80

(1) $\alpha$ - endosulfan, (2) $\beta$-endosulfan, (3) Endosulfan sulfate

(4) Endodiol

(a) without Pseudomonas aeruginosa

(b) with Pseudomonas aeruginosa

The unit T8 (Pseudomonas aeruginosa with Tween 80), showed optimum degradation of endosulfan isomers. The addition of Tween $80(0.1 \mathrm{~g} / \mathrm{L})$ in the treatment unit T8 might have emulsified the endosulfan, thereby increasing the amount of insecticide in contact with the soil bacteria. Surfactant even at very low concentration was shown to enhance the biodegradation of certain xenobiotics in soil [18]. The nonionic surfactant (Novel 1111412-56) at $10 \mu \mathrm{g} / \mathrm{mL}$ added to the surface of lime silt loam soil enhanced the biodegradation of phenanthrene and biphenyl [6].

The accumulation of metabolite endosulfan sulfate is more persistent and is similarly toxic as the alpha and beta isomers of endosulfan. Under alkaline conditions the transformation of endosulfan-to-endosulfan diol was observed which was reported to be less toxic than endosulfan sulfate. These observations are in accordance with an earlier study, where an enriched bacterial culture (Mycobacterium $s p$ ) was shown to metabolize the two isomers of endosulfan differentially. Alpha-isomer was subjected to the oxidation and converted into endosulfan hydroxy ether, endosulfan diol and some uncharacterized metabolites. Beta endosulfan appears to be much more persistent in soil than the alpha-isomers under flooded and non-flooded condition [19]. A number of studies carried out on the degradation of endosulfan in aqueous system, where beta endosulfan is degraded faster than the alpha isomers [20]. The degradation of soil 
bound alpha endosulfan is always faster than beta-isomers under both aerobic and anaerobic conditions [21, 22]. The formation of endosulfan sulfate was quite high in non-flooded experiments [23, 24]. In uninoculated soils, there is a formation of endosulfan sulfate. This indicates that living organisms may be necessary to bring about the oxidation of endosulfan-to-endosulfan sulfate [25]. The degradation of soil bound endosulfan was slow; the reason may be due to the adsorption of endosulfan to soil particles or because of the presence of other carbonaceous materials in the soil [26].

Most of the research has concentrated on the degradation of endosulfan in liquid medium [19]. A few studies carried out on the degradation of endosulfan in soil have been without surfactant amendment [26]. This study proves that Pseudomonas aeruginosa combined with Tween 80 is able to achieve $92 \%$ degradation of endosulfan in contaminated soil. Hence, surfactant enhanced degradation studies is a promising approach for remediation of endosulfan contaminated soils.

Acknowledgement: We thank CSIR, New Delhi for the financial support throughout my period of study

\section{REFERENCES}

[1] Kwon, G.S., Kim, J.E., Kim, T.K., Sohn, H.Y., Koh, S.C., Shin, K.S., Kim, D.G. (2002): Klebsiella pneumoniae KE-1 degrades endosulfan without formation of the toxic metabolite endosulfan sulfate. - FEMS Microbiological Letters 215: 255-289.

[2] Kullmann, S.W., Matsumura, F. (1996): Metabolic pathway utilized Phanerochaete Chrysosporium for degradation of the cyclodine pesticide endosulfan. - Applied Environmental Microbiology 62: 593-600.

[3] Baar, D.P., Aust, S.A. (1987): Mineralization of recalcitrant environmental pollutants by white rot fungus. - In: Proc. National conference on Hazardous materials 2: 146-151.

[4] Angela, Link (2000): Effect of non ionic surfactants on dissolution of polycyclic aromatic hydrocarbons from coal tar. - Practical Periodical Hazardous Toxic Radioactive Waste Management 4: 78-81.

[5] Bury, S.J., Miller, C.A. (1993): Effect of micellar solubilization on biodegradation rates of hydrocarbons. - Environmental Science Technology 27: 104-110.

[6] Aronstein, B.N., Alexander, M. (1993): Effect of non-ionic surfactant added to the soil surface on the biodegradation of aromatic hydrocarbons within the soil. - Applied Microbiology Biotechnology 39: 386-390.

[7] Singer, M.E., Finnerty, W.R. (1984): Microbiol metabolism of straight chain and branched alkanes. - In Atlas, R.M. (ed) Petroleum microbiology, Macmillan pub. New York.

[8] Wong, J.W.C., Fang, M., Zhao, Z., Xing, B. (2004): Effect of surfactants on solubilization and degradation of phenanthrene under thermophilic conditions. - Journal of Environmental Quality 33: 2015-2025.

[9] Volkering, F., Breure, A.M., Anderi, J.G., Rulkens, W.H., Andel, J.G. (1995): Influence of nonionic surfactants on bioavailability and biodegradation of polycyclic aromatic hydrocarbons. - Applied and Environmental Microbiology 61: 1699-1705.

[10] Kookana, R.S., Baskaran, S., Naidu, R. (1998): Pesticide fate and behavior in Australian soils in relation to contamination and management of soil and water: a review. Australian Journal of Soil Research 36: 715-764.

[11] Haarstad, K., Fresvig, M. (2000): The influence of organic matter and pH on DDT aqueous solubility. - Soil Sediment Contamination 9: 347-358. 
[12] Trivedy, R.K., Goel, P.K. (1986): Chemical and biological methods for water pollution studies. - Environmental Publications, Karad.

[13] Miller, R.M., Zhang, Y. (1997): Measurement of biosurfactant enhanced solubilization and biodegradation of hydrocarbons. Methods in Biotechnology, Bioremediation protocols - Sheeman human press, Totowa NJ, 2: 59-66.

[14] Awasthi, N., Ahuja, R., Kumar, A. (2000): Factors influencing the degradation of soil applied endosulfan isomers. - Soil Biology and Biochemistry 32: 1697-1705.

[15] Kovacs, M.F. (1965): Thin layer chromatography for pesticide residue analysis. Journal of Associated Agricultural Chemistry 48: 1018-1022.

[16] Awasthi, N., Singh, A.K., Jain, R.K., Khangorat, B.S., Kumar, A.(2003): Degradation and detoxification of endosulfan isomers by a defined co-culture of two Bacillus strains. - Applied Microbiology and Biotechnology 62: 279-283.

[17] Atlas, R.M., Cerniglia, C.E. (1995): Bioremediation of petroleum pollutants. Bioscience 45: 332-338.

[18] Haigh, S.D., Alcock, R. (1996): A review of the interaction of surfactants with organic contaminants in sewage sludge. - Lancaster University, U.K. 185: 161-170.

[19] Sutherland, T.D., Weir, K.M., Lacey, M.J., Horne, I., Russel, R.J. (2002): Gene cloning and molecular characterization of a two-enzyme system catalyzing the oxidative detoxification of $\beta$-endosulfan. - Journal of Applied Microbiology 92: 541-548.

[20] Guerin, T.F., Kennedy, I.R. (1992): Distribution and dissipation of endosulfan and related cyclodienes in sterile aqueous system. Implications for studies on biodegradation. - Journal of Agricultural and Food Chemistry 40: 2315-2323.

[21] Sethunathan, N., Megharaj, M., Chen, Z.L., Williams, B.D., Lewis, G., Naidu, R. (2004): Algal degradation of a known endocrine disrupting insecticide alpha endosulfan, and its metabolite endosulfan sulfate, in liquid medium and soil. - Journal of Agricultural Food Chemistry 57: 3030-3036.

[22] Kwon, G.S. Yong sohn, H., Sunshin, K., Eungbin, K., Seo, B.I. (2005): Biodegradation of the organochlorine insecticide endosulfan and the toxic metabolite endosulfan sulfate by Klebsiela oxytoca KE-8. - Applied Microbiology and Biotechnology 67: 845-850.

[23] Guerin, T.F. (2001): A biological loss of endosulfan and related chlorinated organic compounds from aqueous systems in the presence and absence of oxygen. Environmental Pollution 115: 219-230.

[24] Ghadiri, H., Rose, C.W. (2001): Degradation of endosulfan in a clay soil from cotton farms of western queensland. - Journal of Environmental Management 62: 155-169.

[25] Schmidt, W.F., Hapeman, C.J., Fettinger, J.C., Rice, C.P., Bilboutian, S. (1997): Structure and asymmetry in the isomeric conversion of beta to alpha endosulfan. Journal of Agricultural and Food Chemistry 45: 1023-1026.

[26] Sutherland, T.D., HorneI, P., Lacey, M.J., Harcourt, R.L., Russel, R.J., Oakeshott, J.G. (2000): Enrichment of an endosulfan degrading mixed bacterial culture. - Applied Environmental Microbiology 66: 2822-2828. 